(C) <2018>. This manuscript version is made available under the CC-BY-NC-ND 4.0 license http://creativecommons.org/licenses/by-nc-nd/4.0/

The definitive publisher version is available online at 10.1016/j.eneco.2018.11.001 


\title{
Is hub-based pricing a better choice than oil indexation for natural gas?
}

\author{
Evidence from a multiple bubble test
}

(Published by Energy Economics, 76, 495-503)

Dayong Zhang ${ }^{1}$, Tiantian Wang ${ }^{1}$, Xunpeng $\mathrm{Shi}^{2,3,4^{*}}$, and Jia Liu ${ }^{5}$

1. Research Institute of Economics and Management, Southwestern University of Finance and Economics, China.

2. Australia-China Relations Institute, University of Technology Sydney, Australia;

3. Center of Hubei Cooperative Innovation for Emissions Trading System \& School of Low Carbon Economics, Hubei University of Economics, Wuhan, Hubei Province 430205, China

4. Energy Studies Institute, National University of Singapore, Singapore.

5. Salford Business School, University of Salford, UK.

* Corresponding author: Xunpeng Shi, Email: xunpeng.shi@gmail.com; Tel. +61 431 002760 .

\begin{abstract}
Oil indexation and hub-based pricing are two competing pricing mechanisms in the international natural gas markets. The debates over whether hub-based pricing is preferable to oil indexation have become intense among academics and practitioners, for example, whether and when East Asia should adopt hub pricing. This paper contributes empirically to the debate using a multiple bubble test. Adopting the generalized sup augmented Dickey-Fuller test proposed by Phillips et al. (2015), we show that more explosive bubbles exist in Japan and European gas prices than in the US prices. The argument is that hub-based pricing mechanism can better reflect fundamental values in the gas markets and thus is less subject to speculations. Given the recent trend of financialization in energy markets, gas prices are more likely to deviate from fundamental values when they are not clear to investors. Although oil indexation is simple and has been an effective tool over the past few decades, our results suggest that hub pricing is associated with less extreme price movements in the market and thus is a better choice for both policy makers and practitioners.
\end{abstract}

Keywords: Hub pricing; Bubbles; Natural gas; Oil indexation; JEL: G14; Q31 Q41 


\section{Introduction}

A heated debate has emerged recently in the literature over the pricing of natural gas. Two competing pricing mechanisms, namely, oil indexation and gas-on-gas competition (GOG, spot, or hub-based) pricing mechanisms, coexist in the international natural gas markets. The US Henry hub gas price, for example, is the main representative of a GOG pricing system, whereas oil indexation has a dominant role in the East Asian natural gas markets (IGU, 2017). Europe has been in the process of shifting from oil indexation to the US pricing model (Grandi, 2014; Shi, 2016). East Asia is in the process of creating its own benchmark gas prices to use as the foundation of hub pricing. China, Japan, and Singapore have opened gas exchanges, and Singapore created some liquefied natural gas (LNG) price indexes, with the development of futures markets (Shi and Variam, 2016, 2017).

Although oil indexation is well established and has helped gas gain market share over the past few decades, it is under intensive debates recently (Stern, 2014; Komlev, 2016). Oil indexation was initially proposed by the Netherlands in the 1960s in the policy paper known as the Nota de Pous. The price of natural gas is based on the "netback value" of alternative fuels, such as gasoline and heavy fuel oil. The formula takes the value at the point of sale and then backward by deducting the cost of transportation and profit. This price mechanisms guaranteed that gas would be more competitive than petroleum products and thus gain market share for it (IEA, 2013).

The arguments in favor of a GOG pricing mechanism are based on the fact that natural gas and crude oil are not perfect substitutes and have different fundamental 
driving factors (Zhang et al., 2018a). If the true fundamental value is not known, prices tend to deviate from it, which results in abnormal price dynamics. ${ }^{1}$ International energy markets have experienced an increasing trend of financialization since the 2008 global financial crisis (Zhang, 2017), which means that the price of energy commodities, such as oil and gas, are more likely to behave like financial assets. In this sense, noise trading, speculation, and asset bubbles are more likely to appear in international energy markets. Su et al. (2017), for example, find that oil prices are shown to have multiple explosive bubbles. The substantial gaps in prices between North America, Europe, and Asia were also used as reasons to criticize oil indexation pricing mechanisms (Shi and Variam, 2016), and empirically it has been demonstrated that such gaps are due to different pricing mechanisms more than market fundamentals (Zhang et al., 2018a).

Despite an increasing volume of voice calling for hub-based pricing system (e.g., (Shi and Variam, 2016, 2017; Stern, 2014)), oil indexation is still considered "the best remedy for market failure" (Komlev, 2016) and has been support by many producers. The rationale for oil indexation over hub pricing (e.g., Komlev, 2016) comprises the following three main points: price hubs can represent only a limited share of total demand and supply in the market, or "residual market segment," because of the prevailing oil indexation contracts; index prices can act as price anchors for hub prices; and market failure is more likely to happen with GOG competition pricing.

\footnotetext{
${ }^{1}$ Fundamental value and price anomalies are discussed in the behaviorial finance literature, for example, Shleifer and Vishny (1997).
} 
There is also an argument that, compared to the gas market, the oil market is larger and contains more market players, and thus it is less likely to be manipulated.

A key issue in this debate is which pricing mechanism is better for the natural gas markets. Which one is the best remedy for market failure: oil indexation or hub pricing? While the term "market failure" is an economic concept used by Komlev (2016) describing the situation that suboptimal prices lead to consistent imbalances in natural gas market, it happens when prices fail to respond demand and supply side shocks. The key point of our argument is that oil indexation cannot properly reflect market fundamentals in natural gas market (Stern, 2014), which is one of the main causes of the "Asian Premium" (Zhang et al., 2018a). How this issue is addressed has strong policy implications and crucial practical relevance because both try to avoid extreme price movements or persistent imbalance of demand and supply. Technically, these arguments can be transformed into a test of asset bubbles in natural gas markets. A better market mechanism should be more efficient and less likely to be subject to asset bubbles.

Borrowing from the concept in financial economics, a better market should be efficient - in other words, prices should be able to reflect the fundamental values of an underlying asset and respond to information quickly. Without clear information on the fundamental value, the price of an asset can deviate significantly, which can result in pricing bubbles. If the market is inefficient and investor trading behavior can influence asset prices, then speculation is also possible. Noise traders' risk (De Long et al., 1990a) and speculative trading (De Long et al., 1990b) in financial markets can 
trigger excess price movements or asset bubbles, which are costly and can generate significant welfare losses.

Natural gas markets are geographically segmented into three major regions, namely, the North American market, the European market, and the East Asian market (IEA, 2013). Each market has distinctive characteristics: a purely hub-based pricing system (the US), a mixture of hub pricing and oil indexation (Europe), and a regime predominantly based on oil indexation (East Asia or the Japanese market in particular). This clear division across natural gas markets enables us to empirically comment on the effectiveness of the competing pricing mechanisms based on historical data. A simple hypothesis based on this argument is as follows: A hub-based pricing system, by better reflecting market demand and supply factors and thus the fundamental values of natural gas, can provide a more efficient market system that is associated with fewer price bubbles. Alternatively, we would expect more explosive price movements to exist in the Japanese gas price than the European price, whereas the US price should have the fewest.

This paper contributes to the recent debates on international natural gas pricing mechanisms (e.g. Stern, 2014; Komlev, 2016). While Stern (2014) is a strong supporter for the hub-based pricing system, Komlev (2016) clearly stands on the opposite side and gives credit to the oil indexation system. Both authors focusing on the practical facts and rationales but without clear statistical evidence. Adopting the generalized sup ADF test proposed by Phillips et al. (2015), we can comment on the question of which pricing mechanism can better reflect fundamentals in the 
international natural gas markets and less subject to speculations. Thus, our paper has clear value that contributes to these debates. Moreover, in terms of real practice, the East Asia and Central and East Europe have remained the major battlegrounds between oil indexation and hub pricing (EIA, 2017), which also gives us practical motivation.

The remainder of this paper is structured as follows. Section 2 reviews the relevant literature. Section 3 briefly introduces the methodology of testing multiple bubbles, namely, the generalized sup augmented Dickey-Fuller (GSADF) test proposed by Phillips et al. (2015). Data used in our empirical study are summarized in section 4, and empirical results are reported in section 5. The last section concludes with a policy discussion.

\section{Literature review}

\subsection{Decoupling of oil and gas prices}

A large volume of literature has recently emerged to investigate pricing mechanisms for natural gas. Many of them start with empirical tests on of whether gas and oil prices have been decoupled (e.g., Brown and Yücel, 2008; Erdos, 2012; Hartley et al., 2008; Ramberg et al., 2017; Serletis and Shahmoradi, 2005). The motivation for these studies is the observed price turmoil in oil and gas markets and the apparent divergence in the price of these two commodities. This phenomenon became clearer after the US shale gas revolution and was further amplified by the 2008 global financial crisis (Zhang et al., 2018a). 
The methodology typically used in testing the relationship between oil and gas is the cointegration approach (Brown and Yücel, 2008), which reflects the long-term relationship between oil and natural gas prices. In other words, given the oil indexation hypothesis, one would expect natural gas prices to be bound with oil prices in the long-run. There might be a temporary deviation in the long-run relationship, but an error correction mechanism exists to restore equilibrium. The empirical results, however, have yet to reach a consensus. For example, Brown and Yücel (2008) find that the weekly oil and gas prices in the US are cointegrated with a stable long-run relationship. Hartley et al. (2008) also confirm the error correction mechanism in the US market with longer monthly time-series data. They suggest that the link between gas and oil prices is indirect and show that short-term deviation is mainly due to fundamental demand/supply factors, such as inventory and weather. Asche et al. (2006) support a single-market hypothesis in the UK primary energy market, with a cointegrated relationship among oil, gas, and electricity prices. Regnard and Zakoian (2011) also confirm that oil prices can be used to predict natural gas prices, and they find a cointegration relationship between the one-month Brent price and the natural gas price in the Zeebrugge (Belgium) market over the period 2000-2005.

The positive evidence of a long-term link between oil and gas prices is found mainly before the 2008 global financial crisis and thus generally predates the majority of the shale gas revolution, which, according to a series of research papers (e.g., Caporin and Fontini, 2017; Geng et al., 2016), proved to have strong impacts on the natural gas market. Because of the new features in the international gas market, more recent 
studies have started to challenge the long-run relationship between oil and gas prices. For example, Ramberg and Parsons (2012) find structural breaks between oil and gas prices in the US market. Erdos (2012) suggests that the long-run oil-gas link in the US market is valid only until 2009. Zhang et al. (2017b) find that apart from the global financial crisis, the structural low oil prices linked to changing fundamentals is also a factor that leads to structural break in the oil-gas relationship. Empirical works by Brigida (2014) and Geng et al. (2016) suggest that the relative prices of natural gas and crude oil follow a state-dependent regime-switching model. Batten et al. (2017) focus on the dynamic linkage between these two commodities and suggest that the determinants of oil and gas prices are different. They also suggest that GOG in the US market and the shale gas revolution contribute to the decoupling of oil and gas.

The US market has had a hub pricing system for decades, and thus the long-run boundedness of oil-gas prices loses its foundation. Hub pricing is supposed to be able to better reflect the fundamental value of natural gas (Shi and Variam, 2016; Stern, 2014; Zhang et al., 2018a). In other words, the hub price of natural gas is determined by demand and supply in the natural gas market. On the contrary, given the explicit oil indexation, natural gas prices in the European and Japanese markets still depend heavily on the price of crude oil (Zhang et al., 2018a). Evidence on these two major natural gas markets, however, has started to show their potential decoupling. For example, Zhang and Ji (2018) uses a long-memory approach to investigate the dynamic links of natural gas prices in three markets with the Brent oil price and find temporary decoupling in Europe and Japan. Shen et al., (2018) finds that extreme 
market risks can transmit to gas prices even in hub-based pricing system.

\subsection{From oil indexation to hub pricing}

Since the global financial crisis in 2008, international natural gas markets have changed dramatically. Although US prices remain historically low, prices in the other two major markets (i.e., Europe and Japan) have increased significantly. This further reinforces concerns by both policy makers and practitioners on the feasibility of moving from oil indexation to pricing hubs (e.g., Shi and Variam, 2017). European energy market regulators are more active in reforming European natural gas markets. Stern (Stern, 2014) describe the second half of the 2000s as "the perfect storm," which included the elimination of destination clauses, the arrival of third-party access, and, most importantly, the emergence of pricing hubs. IGU (2015) finds that in 2011/12, 45\% of the gas trade in Europe took place through pricing hubs. Moreover, an increasing number of voices support establishing gas hubs in East Asia, for example, Shi and Variam (2016, 2017) and Zhang et al. (2018a).

The main argument in IEA (2013), Stern (Stern, 2014), and Zhang et al. (2018a) is that oil and natural gas are not necessarily substitutes and have different underlying fundamentals. Their idea is consistent with the efficient market hypothesis (EMH) introduced by Fama (1965) and has become one of the foundational pillars of modern finance theory. The main argument is very simple: the price should reflect the fundamental value of the underlying asset, and in an efficient market it should respond to shocks accurately and quickly. Stern's (Stern, 2014) two problems can be considered an application of the EMH in the natural gas market. Pricing hubs enable 
gas prices to better reflect market fundamentals, and a properly functional pricing hub should have rapid price adjustment that responds to information.

Komlev (2016), who represents mostly the interests of gas exporters, criticizes the recent European reforms and argues that oil indexation is still the best remedy for natural gas market failure. He suggests that oil and natural gas remain substitutes even in Europe, which justifies the initial rationale for oil indexation. Current global natural gas prices are the result of oil indexation. Oil indexation pricing remains the prevailing system in Asia, and even the price in a hub is closely linked with indexed prices. Although most of the recent research concurs on the decoupling of oil and gas prices in the US, Zhang and Ji (2018) find that the deviation of oil indexation in Europe and Japan could be temporary.

The marketization and liberalization of the natural gas market toward a properly functional hub often take decades, and the process is costly. Policy makers in East Asia are particularly cautious and need to learn more about developments in Europe (Shi, 2016). The UK National Balancing Point (NBP), Netherland Title Transfer Facility (TTF), and German Net Connect Germany (NCG) hubs have played a vital role in the reform of European gas markets (Heather, 2012; Hulshof et al., 2016). Miriello and Polo ( 2015) review the development paths for natural gas hubs in Europe and find that although Germany and Italy consume large quantities of gas, only a small share is traded through their pricing hubs, and the majority of the gas consumed is bought through long-term contracts. In general, however, they find that GOG reforms have proven to be effective. 


\subsection{Financialization, bubbles, and regional natural gas prices}

A recent strand of the literature has advanced the concept of energy market financialization (e.g., Cheng and Xiong, 2014; Zhang, 2017; Zhang and Zhang, 2017). The concept does not simply link energy prices, such as oil prices, to financial markets (e.g., Broadstock et al., 2012); rather, it emphasizes that energy commodities have started to demonstrate the characteristics of a financial product. The crude oil market, for example, is considered an alternative investment by international investors (Sari et al., 2012). Nicolau and Palomba (2015) suggest that crude oil is still the most used instrument for hedging and speculation during a period of financial turmoil. As a consequence, models in financial markets can be used to understand the dynamics of energy prices (e.g., Zhang et al., 2018b; Zhang and Zhang, 2017; Zhang and Wu, 2018).

Kaufmann (2011), for example, suggests that the volatile oil price movement between 2007 and 2008 is due to both market fundamentals and speculative trading in the market. Basher and Sadorsky (2016) use a battery of volatility models to investigate the hedging performance of oil against emerging market stock prices. Zhang (2017) studies the interactions between oil price shocks and major stock market returns. The evidence shows that the dynamics of oil prices reflect more movement in the global financial market, not vice versa. The 2008 global financial crisis has also been found to have profound impacts on global markets.

One of the problems with financialization is that speculative trading (e.g., Hache and Lantz, 2013) can exist and cause extreme price movements, or price bubbles. The 
extreme price movements in the international oil markets since the 2008 global financial crisis have triggered a series of studies to test and date the existence of abnormal price fluctuations. For example, Lammerding et al. (2013) find strong evidence of speculative bubbles in the recent oil price movements using a Markov-switching state space approach. Zhang and Yao (2016) explores dynamic bubbles of oil prices and predicts their crash time. Using state-space model and the log-periodic power law (LPPL) model, they find that bubble exists for oil prices between November 2001 and July 2008. The efficiencies of energy portfolios in 2008 also appear different from those of other periods, when natural gas has the highest weight in all energy portfolios in this period (Zhang and Chen, 2018). Tsvetanov et al. (2016) use the method proposed by Phillips and Yu (2011) and Phillips et al. (2015) to test for multiple bubbles in the West Texas Intermediate (WTI) spot and futures oil prices. Caspi et al. (2018) use the same method to detect price bubbles in US oil prices between 1876 and 2014. Gronwald (2016) reports explosive oil price movements around the 2008 global financial crisis. Su et al. (2017) find six bubbles in WTI crude oil prices during 1986-2016. Sharma and Escobari (2018) also use GSADF method to test the explosive behavior of three energy prices (WTI crude oil, heating oil and natural gas) in the US market, but the article only analyze whether there are bubbles in energy prices.

Technically, a bubble means deviation from the fundamental value of the underlying asset (Blanchard and Watson., 1982). It is more likely to happen when the fundamental value is not clear to investors. Although the global oil market is liquid 
and large, the fundamentals are not well reflected in oil prices because the financialization of oil products has created too much speculation, which dwarfs the role of market fundamentals. The globalized market also makes it difficult to measure fundamentals worldwide and thus leaves room for speculation. Unlike crude oil, which has a global market, natural gas markets are not mature and generally segmented and have different fundamental driving factors (Ji et al., 2014; Zhang et al., 2018a). This combination of indexation to global oil markets and regional differences distort signals from gas prices and thus causes speculation and irrational investment. Further development of gas pricing mechanisms that can reflect regional gas market fundamentals are needed.

The hypothesis of this paper is that a hub-based pricing system allows natural gas prices to reflect the fundamental value of natural gas itself, whereas linking directly to crude oil prices in the oil indexation system fails to incorporate gas-specific characteristics, and thus leading to potential mispricing. Moreover, GOG competition in a hub enables the market to respond quickly to new information, which improves the efficiency of the market. In a less efficient market (i.e., oil indexation market), natural gas prices are more likely to be affected by speculation or irrational investment behavior, which then leads to persistent price deviation from fundamental values. In other words, we would expect to see more abnormal price fluctuations with oil indexation than in a hub-pricing system. 


\section{Methodology: Testing for multiple bubbles}

The basic method used in this paper is developed by Phillips and Yu (2011) and then extended by Phillips et al. (2015) to identify multiple bubbles. Their general idea is to use a right-tailed unit-root test (i.e., the augmented Dickey-Fuller test) to detect any potential extreme behavior in the series.

Empirical tests of rational bubbles before the development of Phillips and Yu (2011) test often use standard unit-root test based on Campbell and Shiller (1988), which do not allow for extreme behavior. A stationary (or cointegrated system in a multivariate case) process would indicate that price returns to its fundamental values, whereas a nonstationary unit-root result would suggest a persistent price deviation from the fundamental value, which indicates the existence of bubbles (e.g. Craine, 1993; Zhang et al., 2017a). Phillips and Yu (2011) move one step further from this literature and show that asset prices can deviate from fundamental values in a mildly extreme manner. They then develop a rolling-windows estimation based on ADF regressions. The largest test statistics (the sup) are used as the right-tailed statistic.

For example, if we let $y_{t}$ be a time-series variable with total observations of $T, \mathrm{r}_{1}$ and $r_{2}$ are the starting position and ending position of the rolling windows, and the size of the window is $r_{w}=r_{2}-r_{1}$. The typical ADF regression can be written as

$$
\Delta y_{t}=\hat{c}_{r_{1}, r_{2}}+\hat{\beta}_{r_{1}, r_{2}} y_{t-1}+\sum_{i=1}^{k} \hat{\phi}_{r_{1}, r_{2}}^{i} \Delta y_{t-i}+\hat{\varepsilon}_{t},
$$

where $\mathrm{c}, \beta$, and $\phi$ are parameters to be estimated, the error term is $\varepsilon_{\mathrm{t}} \sim \mathrm{N}\left(0, \mathrm{o}^{2}\right)$, and $\mathrm{k}$ is the number of the lags determined by information criteria. The null hypothesis of a 
standard $\mathrm{ADF}$ test is that $y_{t}$ has a unit root against the alternative of $\beta<0$, or it is stationary. Phillips and Yu (2011) extend the basic ADF principle to allow for the right-sided alternative $\beta>0$ or to consider an extreme alternative hypothesis.

We normalizing the total observation to 1 and denote $r_{w}$ as the share of data from the full sample. The number of observations in each window is therefore $T_{w}=\left[r_{w} T\right]$, and $[\bullet]$ represents the integer part of the number in the brackets. If the smallest window size is given as $r_{0}$, then a sequence of test statistics based on the forward expanding samples can be derived. A sup of these statistics is defined as sup ADF (SADF) test statistics, as follows:

$\operatorname{SADF}\left(r_{0}\right)=\sup _{r_{\mathrm{a}}=\left[r_{0,1}, 1\right]} A D F_{0}^{r_{2}}$.

In reality, there are often multiple bubbles. The SADF test, however, can detect only one bubble. To cope with this problem and detect more than one bubble in the series, Phillips et al. (2015) develop the generalized sup ADF test (GSADF). A major difference here is allowing the starting point in equation (2) to change as well.

$\operatorname{GSADF}\left(r_{0}\right)=\sup _{r_{\mathrm{a}}}=\left[r_{0^{0}} 1\right]_{a} r_{1}=\left[0, r_{\mathrm{a}}-r_{0}\right] A D F_{r_{1}}^{r_{2}}$.

Phillips et al. (2015) develop the limited distribution of these test statistics and provide asymptotic critical values on both the SADF and GSADF statistics. In the case of multiple bubbles, the forward expansion method tends to be less powerful in identifying more bubbles after the first one. So they propose a date-stamping strategy with a double recursive test procedure and backward sup ADF (BSADF) test method, 
which is based on backward-expanding samples:

$\operatorname{BSADF}\left(r_{0}\right)=\sup _{r_{1}}=\left[0_{0} r_{2}-r_{0}\right] A D F_{r_{1}}^{r_{2}}$,

Then the GSADF test can be written as:

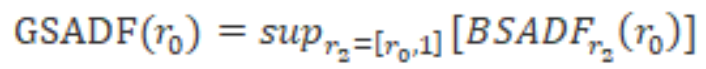

The sequence of BSADF test statistics will be compared to the critical value of the

GSADF test. Whenever the statistic exceeds the critical value, there is a bubble, which is then considered to burst when the BSADF statistic falls below the critical value.

\section{Data}

All data are collected from World Bank commodity price data (the Pink Sheet). They are in monthly frequency from January 1982 to October 2017. Oil prices are denominated in nominal US dollars per barrel, and natural gas prices are in dollars per MMBTU (millions of British thermal units). For oil, we look at WTI and Brent prices, whereas for natural gas price, we use the Henry Hub Louisiana spot price for the US, LNG import prices (CIF) is used for Japan, and average import border prices and a spot price component are used for Europe (in this data, the UK price is excluded between June 2000 and March 2010).

<Insert Figure 1 here> 
Figure 1 plots the two monthly prices of oil (Brent and WTI) and three natural gas prices separately. Clearly, two oil price series are generally similar, whereas the regional natural gas prices have substantial deviations. After 2008, the US Henry Hub prices are much lower than the other two prices because of the global financial crisis and shale gas revolution (IEA, 2013). Japanese LNG prices increased further to around four times the US price after the Fukushima nuclear power plant accident in 2011, which led to greater imports of LNG for power generation. The price differences are also reflected in Table 1, which summarizes the descriptive statistics for prices as well as the oil-gas price ratios. Among all three gas price series, the average value of Japanese LNG prices is the highest and has the highest volatility, whereas the US Henry Hub prices have both the lowest average value and standard deviation. If we simply consider volatility as a measure of risk in the market, then it is obvious that the US market based on GOG pricing has the lowest risk, whereas the purely oil-indexed Japanese LNG price has the highest risk. More importantly, the simple statistics show that a market with higher risk has to pay higher prices (the Asian premium).

<Insert Table 1 here>

To better illustrate the oil-gas price difference, Figure 2 plots the ratio of Brent and 
WTI prices against three natural gas prices. The patterns in these two sets of ratios are essentially identical. In other words, the results should not be sensitive to the choice of oil prices. Therefore, we use Brent oil prices in all the following empirical studies. It should be noted that 1 barrel of oil is equivalent to 5.55 MMBTU. For the US oil-gas price ratio, the graph contains roughly three stages, with an earlier stage of 10 : 1 and then 6: 1 until the 2008 global financial crisis. Because of the significant fall in natural gas prices and the recovery in oil prices, oil-gas price ratios have become dramatic and extremely volatile. The ratio is much more stable in Europe than in the US. In Japan, a clear structural change occurs in the early 2000s, and the ratio increases significantly during the 2008 global financial crisis. These clear regional differences are consistent with the pricing mechanisms (Zhang and Ji, 2018).

<Insert Figure 2 here>

\section{Empirical results}

\subsection{GSADF bubble test on prices}

Empirical analysis on the multiple bubbles in oil price series has been conducted in some recent papers (e.g., Gronwald, 2016; Su et al., 2017; Caspi et al., 2018), therefore, this paper will not discuss the bubbles in the oil market in detail and use them for reference with respect to natural gas prices. Our results are generally consistent with these existing studies (Su et al., 2017) on oil prices, and therefore the 
application on natural gas prices gives comparable results.

The GSADF test was performed in Eviews with add-in package "Right Tailed ADF Tests" developed by Caspi, I. (2017). The configuration of the GSADF test is standard: we use Bayesian information criteria (BIC) to select the optimal number of lags. Critical values for the GSADF test are taken from 500 Monte Carlo simulations with the actual sample size.

<Insert Figure 3-6 here>

The results are plotted in Figures 3-6 for three natural gas price series and Brent crude oil prices. ${ }^{2}$ In each graph, the price series is plotted (right indexed) on the top. Whenever the BSADF test statistics cross a critical value, a bubble forms, and when the statistics fall below the critical value, it bursts. Shaded areas in each graph show the bubble periods. A summary of all four series is in Table 2.

$<$ Insert Table 2 here>

Clearly, there are significant differences across these price series. A few observations

\footnotetext{
2 The identified bubbles in Brent crude oil price series are roughly consistent with the results for WTI
} reported in Su et al. (2017). Given that our sample ended in October 2017, which is one year longer than in Su et al. (2017), the backward test results differ slightly. 
can be summarized as follows:

1) The US Henry Hub prices have the fewest bubbles, and the timing of these explosive dynamics is clearly different from all other series. The 2008 global financial crisis has some impact on gas prices in the US, but no unusual fluctuation is found during this period.

2) For European gas prices, Japanese LNG prices, and the Brent oil prices, one or two bubbles around 2008 (the global financial crisis period) can be seen clearly. The duration of two explosive price movements in European gas prices and Brent oil prices are almost identical. Japan has one long bubble that connects the bubble periods in the other two markets.

3) Japanese LNG has the most bubbles. More interestingly, if we exclude the global financial crisis period, another unique feature of the Japanese LNG price bubbles is their short duration (from one to four months).

4) Whenever an explosive price movements forms in oil prices, European gas prices and Japanese LNG prices both tend to have bubbles. They also show bubbles even if the oil market does not.

Although the method here does not allow us to perform a formal statistical test, this information shows some strong and interesting evidence as to whether hub pricing is better than oil indexation pricing in the natural gas market.

Recall that Japan has yet to develop a pricing hub, and its natural gas price closely follows oil indexation, whereas the US has a long history of GOG competition in the 
pricing hub. Europe is somewhere in between the other two markets. It features both oil indexation in most of the continental natural gas markets and hub pricing hubs in Northwest Europe such as the UK and the Netherlands. These clear differences in pricing systems give us a chance to evaluate which one will lead to a better natural gas market—and by "better" we mean one likely to keep the market more stable, less likely to have speculative price movements (bubbles), and more efficient. To return to the earlier evidence from the descriptive statistics, it is obvious that the US hub pricing system is associated with the lowest price and the least standard deviation in prices. The Japanese LNG price is highest, consistent with the notion of the "Asian premium" (Zhang et al., 2018a) and suffers from the highest volatility.

The results of our bubble tests show more problems in the natural gas prices in Japan. With oil indexation, whenever there is an unusual price movement (i.e., a bubble) in the international crude oil market, natural gas prices will follow and experience explosive price changes. As the pricing system ignores fundamental values in natural gas, the market tends to react to information irrationally and thus creates more bubbles than are passed from the oil market. The additional bubble pattern becomes more obvious with the recent trend in energy financialization. Table 2 shows that, since the 2008 global financial crisis, five bubbles emerged in Japanese LNG prices, and two bubbles occurred in European prices. Meanwhile, the US Henry Hub prices show no explosive bubbles in the same period. Again, no explicit statistical test exists to show the causality here, but the historical evidence shows that a hub-pricing system is a better choice than oil indexation for maintaining market stability and is more 
efficient in general.

\subsection{GSADF test on oil-gas price ratios}

Assuming that oil prices contain the fundamental value of natural gas, this subsection performs multiple bubble tests on the oil-gas price ratio for the three regional markets. The existence of bubbles in the price ratio indicates that oil prices deviate from natural gas prices in an extreme way. Figures 7-9 plot the GSADF results on oil-gas price ratios in the US, Europe, and Japan.

$<$ Insert Figure 7-9 here>

The results, summarized in Table 3, show cross-market differences. Two explosive price movements are found in the US ratio, in 2009 and 2012. In these periods, oil prices went up dramatically, whereas natural gas prices in the US remain relatively low. The evidence also indicates that US oil and gas prices have largely decoupled since the 2008 global financial crisis. Fewer bubbles are found in the ratios in Japan and Europe, which is reasonable, especially with oil indexation (Japan and Europe).

$<$ Insert Table 3 here> 


\section{Conclusion}

This paper contributes to current debates on international natural gas pricing mechanisms with some up-to-date time-series methods. In recent years there have been increasing calls for establishing GOG competition pricing hubs in Europe and Asia to cope with higher gas prices (relative to the US) and market volatility. Supporting arguments claim that hub pricing can better reflect market fundamentals in natural gas and thus create better efficiency. By contrast, the arguments against hub pricing and in favor of oil indexation suggest that oil indexation is the best remedy for market failure.

Using the Phillips et al. (2015) multiple bubble detecting technique, we empirically study natural gas prices in three major international gas markets. In these markets, the US has a long history of having a pure hub pricing system, and Japanese prices are mainly indexed to crude oil prices, whereas the European market is a more complex mixture of hub pricing and oil indexation. This cross-market difference gives us a chance to join the debate between oil indexation and hub pricing.

Our empirical results show that the oil indexation system (e.g., in Japan) has higher prices, higher volatility, and more frequent pricing bubbles. Because of oil indexation, natural gas prices will experience explosive price movements whenever a bubble forms in crude oil prices. Moreover, unclear information on natural gas fundamental values tends to create even more bubbles than in the oil markets. This tendency became stronger after the 2008 global financial crisis, when the energy market became further financialized (Cheng and Xiong, 2014). The US hub pricing system, 
by better reflecting the fundamental information on natural gas, shows clear differences from the international crude oil markets. The Henry Hub price has noticeably fewer explosive price movements than the other two prices, which is especially noteworthy after the 2008 global financial crisis. Given that the pricing system in Europe is a mixture of the two systems, the number of bubbles there is lower than in Japan but more than in the US. More evidence of oil indexation in Europe is found. The explosive fluctuations in European average prices largely coincide with the bubble periods in Brent crude oil prices.

Two policy implications emerge from our studies. First, the transition from oil indexation to hub pricing should proceed for more efficiency market. Bubbles are destructive forces in any market, and neither policy makers nor consumers, in either exporting or importing countries, want to experience higher risk. From this point of view, our empirical evidence provides clear support for hub pricing and against the claim that oil indexation is a better mechanism to avoid market failure. Furthermore, a better market should be a more efficient market, in which prices should be able to reflect fundamental information accurately and quickly. Without knowing the fundamental values of natural gas, it is hard to achieve market efficiency. These findings have important real implications to policymakers, especially those in the East Asia and Central and East Europe, which are the major battlegrounds between oil indexation and hub pricing (EIA, 2017). They should be more determined to transit to the hub pricing from indexation and establish functional gas trading hub.

Second, both importing and exporting countries, which are often assumed to have 
opposite interests, should cooperate in the change in pricing mechanisms during the transition. This cooperation is based on the argument that spot prices could be higher or lower than oil-indexed prices, and thus hub pricing has a neutral effect for both exporters and importers. A real and fresh example is that after being below oil-indexed prices for long time, the Asian spot LNG price in October 2017 nearly doubled compared to its low in June 2017 and turned out to be higher than oil-indexed prices (Vukmanovic, 2017). Our results further demonstrate that exporters and importers have common interests in terms of market efficiency and thus support the suggestion in the literature that exporters and importers should work together for the transition of pricing mechanisms (e.g., Shi and Variam 2017)).

Acknowledgement: We thank financial support from the National Natural

Science Foundation of China (NSFC) under grant number 71573214 and the 111 Project Grant No. B16040. 


\section{References}

Asche, F., Osmundsen, P., Sandsmark, M., 2006. The UK market for natural gas, oil and electricity: Are the prices decoupled? Energy J. 27, 27-40. https://doi.org/10.5547/ISSN0195-6574-EJ-Vol27-No2-2

Basher, S.A., Sadorsky, P., 2016. Hedging emerging market stock prices with oil, gold, VIX, and bonds: A comparison between DCC, ADCC and GO-GARCH. Energy Econ. 54, 235-247. https://doi.org/10.1016/j.eneco.2015.11.022

Batten, J.A., Ciner, C., Lucey, B.M., 2017. The dynamic linkages between crude oil and natural gas markets. Energy Econ. 62, 155-170. https://doi.org/10.1016/j.eneco.2016.10.019

Blanchard, O.J., Watson., M.W., 1982. Bubbles, Rational Expectations and Financial Markets, in: Paul Wachtel (Ed.), Crises in the Economic and Financial Structure. D.C. Heathand Company, Lexington, MA, pp. 295-316.

Brigida, M., 2014. The switching relationship between natural gas and crude oil prices. Energy Econ. 43, 48-55.

Broadstock, D.C., Cao, H., Zhang, D., 2012. Oil shocks and their impact on energy related stocks in China. Energy Econ. 34, 1888-1895. https://doi.org/10.1016/j.eneco.2012.08.008

Brown, S.P., Yücel, M.K., 2008. What drives natural gas prices? Energy J. 29, 45-60.

Campbell, J.Y., Shiller, R.J., 1988. The Dividend-Price Ratio and Expectations of Future Dividends and Discount Factors. Rev. Financ. Stud. 1, 195-228. https://doi.org/10.1017/CBO9781107415324.004

Caporin, M., Fontini, F., 2017. The long-run oil-natural gas price relationship and the shale gas revolution. Energy Econ. 64, 511-519. https://doi.org/http://dx.doi.org/10.1016/j.eneco.2016.07.024

Caspi, I., 2017. Rtadf: Testing for Bubbles with EViews. J. Stat. Softw. 81, 1-16. https://doi.org/10.18637/jss.v081.c01

Caspi, I., Katzke, N., Gupta, R., 2018. Date stamping historical periods of oil price explosivity: 1876-2014. Energy Econ. 70, 582-587. https://doi.org/10.1016/j.eneco.2015.03.029

Cheng, I.-H., Xiong, W., 2014. Financialization of Commodity Markets. Annu. Rev. Financ. Econ. 6, 419-441. https://doi.org/10.1146/annurev-financial-110613-034432

De Long, J.B., Shleifer, A., Summers, L.H., Waldmann, R.J., 1990a. Noise Trader Risk in Financial Markets. J. Polit. Econ. 98, 703-738. https://doi.org/10.1086/261703

De Long, J.B., Shleifer, A., Summers, L.H., Waldmann, R.J., 1990b. Positive Feedback Investment Strategies and Destabilizing Rational Speculation. J. Finance 45, 379-395. https://doi.org/10.1111/j.1540-6261.1990.tb03695.x

EIA, 2017. Perspectives on the Development of LNG Market Hubs in the Asia Pacific Region. U.S. Energy Information Administration, Washington D.C.

Erdos, P., 2012. Have oil and gas prices got separated? Energy Policy 49, 707-718. 
Fama, E.F., 1965. The Behavior of Stock-Market Prices. J. Bus. 38, 34-105. https://doi.org/10.1017/CBO9781107415324.004

Geng, J.B., Ji, Q., Fan, Y., 2016. The impact of the North American shale gas revolution on regional natural gas markets: Evidence from the regime-switching model. Energy Policy 96, 167-178. https://doi.org/10.1016/j.enpol.2016.05.047

Grandi, L., 2014. European gas markets: From oil indexation prices to spot prices? Energy Brains-Energy Analysis.

Gronwald, M., 2016. Explosive oil prices. Energy Econ. 60, 1-5. https://doi.org/10.1016/j.eneco.2016.09.012

Hache, E., Lantz, F., 2013. Speculative trading and oil price dynamic: A study of the WTI market. Energy Econ. 36, 334-340. https://doi.org/10.1016/j.eneco.2012.09.002

Hartley, P.R., Medlock III, K.B., Rosthal, J.E., 2008. The relationship of natural gas to oil prices. Energy J. 29, 47-65.

Heather, P., 2012. Continental European Gas Hubs: Are they fit for purpose. OIES, Oxford.

Hulshof, D., van der Maat, J.-P., Mulder, M., 2016. Market fundamentals, competition and natural-gas prices. Energy Policy 94, 480-491. https://doi.org/http://dx.doi.org/10.1016/j.enpol.2015.12.016

IEA, 2013. Developing a Natural Gas Trading Hub in Asia: Obstacles and Opportunities. International Energy Agency, Paris.

IGU, 2017. Wholesale Gas Price Survey - 2017 Edition.

IGU, 2015. Wholesale Gas Price Survey - 2015 Edition. International Gas Union, Norway.

Ji, Q., Geng, J.-B.B., Fan, Y., 2014. Separated influence of crude oil prices on regional natural gas import prices. Energy Policy 70, 96-105. https://doi.org/http://dx.doi.org/10.1016/j.enpol.2014.03.019

Kaufmann, R.K., 2011. The role of market fundamentals and speculation in recent price changes for crude oil. Energy Policy 39, 105-115. https://doi.org/10.1016/j.enpol.2010.09.018

Komlev, S., 2016. Oil indexation: The best remedy for market failure in the natural gas industry. Demian Literacy Agency, St. Petersburg.

Lammerding, M., Stephan, P., Trede, M., Wilfling, B., 2013. Speculative bubbles in recent oil price dynamics: Evidence from a Bayesian Markov-switching state-space approach. Energy Econ. 36, 491-502. https://doi.org/10.1016/j.eneco.2012.10.006

Miriello, C., Polo, M., 2015. The development of gas hubs in Europe. Energy Policy 84, 177-190. https://doi.org/http://dx.doi.org/10.1016/j.enpol.2015.05.003

Nicolau, M., Palomba, G., 2015. Dynamic relationships between spot and futures prices. The case of energy and gold commodities. Resour. Policy 45, 130-143. https://doi.org/10.1016/j.resourpol.2015.04.004

Phillips, P.C.B., Shi, S., Yu, J., 2015. Testing for multiple bubbles: Limit theory of real-time detectors. Int. Econ. Rev. (Philadelphia). 56, 1079-1134. https://doi.org/10.1111/iere.12131 
Phillips, P.C.B., Yu, J., 2011. Dating the timeline of financial bubbles during the subprime crisis. Quant. Econom. 2, 455-491. https://doi.org/10.3982/QE82

Ramberg, D.J., Henry Chen, Y.H., Paltsev, S., Parsons, J.E., 2017. The economic viability of gas-to-liquids technology and the crude oil-natural gas price relationship. Energy $\quad$ Econ. https://doi.org/10.1016/j.eneco.2017.01.017

Ramberg, D.J., Parsons, J.E., 2012. The Weak Tie Between Natural Gas and Oil Prices. Energy J. 33, 13-35. https://doi.org/10.5547/01956574.33.2.2

Regnard, N., Zakoïan, J.M., 2011. A conditionally heteroskedastic model with time-varying coefficients for daily gas spot prices. Energy Econ. 33, 1240-1251. https://doi.org/10.1016/j.eneco.2011.02.004

Sari, R., Hammoudeh, S., Chang, C.L., McAleer, M., 2012. Causality between market liquidity and depth for energy and grains. Energy Econ. 34, 1683-1692. https://doi.org/10.1016/j.eneco.2012.02.006

Serletis, A., Shahmoradi, A., 2005. Business cycles and natural gas prices. OPEC Rev. 29, 75-84.

Sharma, S., Escobari, D., 2018. Identifying price bubble periods in the energy sector. Energy Econ. https://doi.org/10.1016/j.eneco.2017.12.007

Shen, Y., Shi, X., Variam, H.M.P., 2018. Risk transmission mechanism between energy markets: A VAR for VaR approach. Energy Econ. 75, 377-388. https://doi.org/10.1016/j.eneco.2018.08.027

Shi, X., 2016. Development of Europe's gas hubs: Implications for East Asia. Nat. Gas Ind. B 3, 357-366. https://doi.org/10.1016/j.ngib.2016.11.001

Shi, X., Variam, H.M.P., 2016. Gas and LNG trading hubs, hub indexation and destination flexibility in East Asia. Energy Policy 96, 587-596. https://doi.org/10.1016/j.enpol.2016.06.032

Shi, X., Variam, H.M.P.H.M.P., 2017. East Asia's gas-market failure and distinctive economics-A case study of low oil prices. Appl. Energy 195, 800-809. https://doi.org/http://doi.org/10.1016/j.apenergy.2017.03.091

Stern, J., 2014. International gas pricing in Europe and Asia: A crisis of fundamentals. Energy Policy 64, 43-48. https://doi.org/http://dx.doi.org/10.1016/j.enpol.2013.05.127

Su, C.W., Li, Z.Z., Chang, H.L., Lobonţ, O.R., 2017. When Will Occur the Crude Oil Bubbles? Energy Policy 102, 1-6. https://doi.org/10.1016/j.enpol.2016.12.006

Tsvetanov, D., Coakley, J., Kellard, N., 2016. Bubbling over! The behaviour of oil futures along the yield curve. J. Empir. Financ. 38, 516-533. https://doi.org/10.1016/j.jempfin.2015.08.009

Vukmanovic, O., 2017. Global LNG-Spot prices climb further on limited supply [WWW Document]. Reuters. URL https://www.reuters.com/article/global-lng/global-lng-spot-prices-climb-further-o n-limited-supply-idUSL8N1N95ZP

Zhang, D., 2017. Oil shocks and stock markets revisited: Measuring connectedness from a global perspective. Energy Econ. 62, 323-333. https://doi.org/10.1016/j.eneco.2017.01.009 
Zhang, D., Ji, Q., 2018. Further evidence on the debate of oil-gas price decoupling: A long memory approach. Energy Policy 113, 58-75.

Zhang, D., Liu, Z., Fan, G. Z., Horsewood, N., 2017a. Price bubbles and policy interventions in the Chinese housing market. Journal of Housing and the Built Environment, 32(1), 133-155.

Zhang, D., Shi, M., Shi, X., 2018a. Oil prices, market fundamentals, and natural gas prices: An explanation of the Asian premium. Energy Econ. 69, 33-41.

Zhang, Y.-J., Chen, M.-Y., 2018. Evaluating the dynamic performance of energy portfolios: Empirical evidence from the DEA directional distance function. Eur. J. Oper. Res. 269, 64-78. https://doi.org/10.1016/j.ejor.2017.08.008

Zhang, Y.-J., Chevallier, J., Guesmi, K., 2017b. "De-financialization" of commodities? Evidence from stock, crude oil and natural gas markets. Energy Econ. 68, 228-239.

Zhang, Y.-J., Yao, T., 2016. Interpreting the movement of oil prices: Driven by fundamentals or bubbles? Econ. Model. 55, 226-240. https://doi.org/10.1016/j.econmod.2016.02.016

Zhang, Y., Yao, T., He, L.-Y., Ripple, R.D., 2018b. Volatility forecasting of crude oil market: Can the regime switching GARCH model beat the single-regime GARCH models? Int. Rev. Econ. Financ. Available online 22 Sept. 2018. https://doi.org/https://doi.org/10.1016/j.iref.2018.09.006

Zhang, Y., Zhang, J., 2017. Volatility forecasting of crude oil market: A new hybrid method. J. Forecast. https://doi.org/10.1002/for.2502

Zhang, Y.J., Wu, Y. Bin, 2018. The dynamic information spill-over effect of WTI crude oil prices on China's traditional energy sectors. China Agric. Econ. Rev. https://doi.org/10.1108/CAER-05-2017-0094 
Tables and Figures

Table 1. Descriptive statistics

\begin{tabular}{lrrrrrrr}
\hline & Mean & Median & Max. & Min. & Std. Dev. & Skewness & Kurtosis \\
\hline US & 3.43 & 2.64 & 13.52 & 1.19 & 2.10 & 1.86 & 7.12 \\
EUR & 5.20 & 3.76 & 15.93 & 1.87 & 3.23 & 1.17 & 3.31 \\
JPN & 6.55 & 4.89 & 18.11 & 2.72 & 4.07 & 1.41 & 3.80 \\
Brent & 42.32 & 28.38 & 133.87 & 9.45 & 31.63 & 1.21 & 3.23 \\
WTI & 41.60 & 29.56 & 133.93 & 11.31 & 28.36 & 1.13 & 3.12 \\
\hline WTI/US & 12.78 & 11.13 & 53.06 & 3.17 & 6.77 & 1.96 & 8.69 \\
WTI/EUR & 7.87 & 7.80 & 12.73 & 2.67 & 1.55 & -0.24 & 3.74 \\
WTI/JP & 6.20 & 5.82 & 11.10 & 2.82 & 1.56 & 0.98 & 3.78 \\
Brent/US & 12.93 & 10.72 & 61.88 & 2.81 & 8.07 & 2.22 & 9.78 \\
Brent/JP & 6.10 & 5.65 & 11.02 & 2.30 & 1.63 & 0.85 & 3.38 \\
Brent/EUR & 7.75 & 7.59 & 12.78 & 2.59 & 1.74 & -0.01 & 3.08 \\
\hline
\end{tabular}

Note: The upper part of this table reports gas (US Henry hub, Europe average and Japan LNG in US dollars per MMBTU) and oil prices (Brent and WTI in dollars per barrel), whereas the lower part summarizes the information on simple oil/gas price ratios. 
Table 2. Multiple bubble test results for price series

\begin{tabular}{|c|c|c|c|c|c|c|c|c|}
\hline & \multicolumn{2}{|c|}{ US Henry Hub } & \multicolumn{2}{|c|}{ Europe } & \multicolumn{2}{|c|}{ Japan LNG } & \multicolumn{2}{|c|}{ Oil (Brent) } \\
\hline & Bubble period & Duration (months) & Bubble period & Duration (months) & Bubble period & Duration (months) & Bubble period & Duration (months) \\
\hline & 03/1986-01/1988 & 23 & 01/1987 & 1 & 02/1987 & 1 & 02/1986-07/1986 & 6 \\
\hline & 04/1988-06/1988 & 3 & 10/1998-07/1999 & 10 & 01/1991-02/1991 & 2 & $10 / 2004$ & 1 \\
\hline & 02/1996 & 1 & $10 / 2000-02 / 2001$ & 5 & $12 / 1996-03 / 1997$ & 4 & $05 / 2005-08 / 2006$ & 16 \\
\hline & 09/2000-03/2001 & 7 & $08 / 2005-12 / 2006$ & 17 & 07/2005-01/2009 & 43 & 06/2007-08/2008 & 15 \\
\hline & 09/2005-12/2005 & 4 & $10 / 2007-12 / 2008$ & 15 & 07/2011 & 1 & $01 / 2015$ & 1 \\
\hline & & & $04 / 2015-10 / 2016$ & 19 & 04/2012-05/2012 & 2 & $12 / 1015-02 / 2016$ & 3 \\
\hline & & & & & $04 / 2015-05 / 2015$ & 2 & & \\
\hline & & & & & $03 / 2016-05 / 2016$ & 3 & & \\
\hline Number of bubbles & & $5(4)$ & & $6(5)$ & & $8(6)$ & & $6(4)$ \\
\hline Average duration & & 7.6 & & 11.2 & & 7.25 & & 7 \\
\hline Maximum duration & & 23 & & 19 & & 43 & & 16 \\
\hline
\end{tabular}

Note: The number of bubbles in brackets excludes those with only one-month duration. 
Table 3. Multiple bubble test results for oil/gas price ratios

\begin{tabular}{|c|c|c|c|c|c|c|}
\hline & \multicolumn{2}{|c|}{ Brent/US Henry Hub } & \multicolumn{2}{|c|}{ Brent/Europe } & \multicolumn{2}{|c|}{ Brent/Japan LNG } \\
\hline & Bubble period & $\begin{array}{l}\text { Duration } \\
\text { (months) }\end{array}$ & Bubble period & $\begin{array}{l}\text { Duration } \\
\text { (months) }\end{array}$ & Bubble period & $\begin{array}{l}\text { Duration } \\
\text { (months) }\end{array}$ \\
\hline & 08/2009-09/2009 & 2 & 03/1986-07/1986 & 5 & $08 / 2005-10 / 2005$ & 3 \\
\hline & 01/2012-08/2012 & 8 & & & & \\
\hline $\begin{array}{l}\text { Number of } \\
\text { bubbles }\end{array}$ & & 2 & & 1 & & 1 \\
\hline Average duration & & 5 & & 5 & & 3 \\
\hline $\begin{array}{l}\text { Maximum } \\
\text { duration }\end{array}$ & & 8 & & 5 & & 3 \\
\hline
\end{tabular}


Figure 1. Plots of Crude oil and natural gas prices
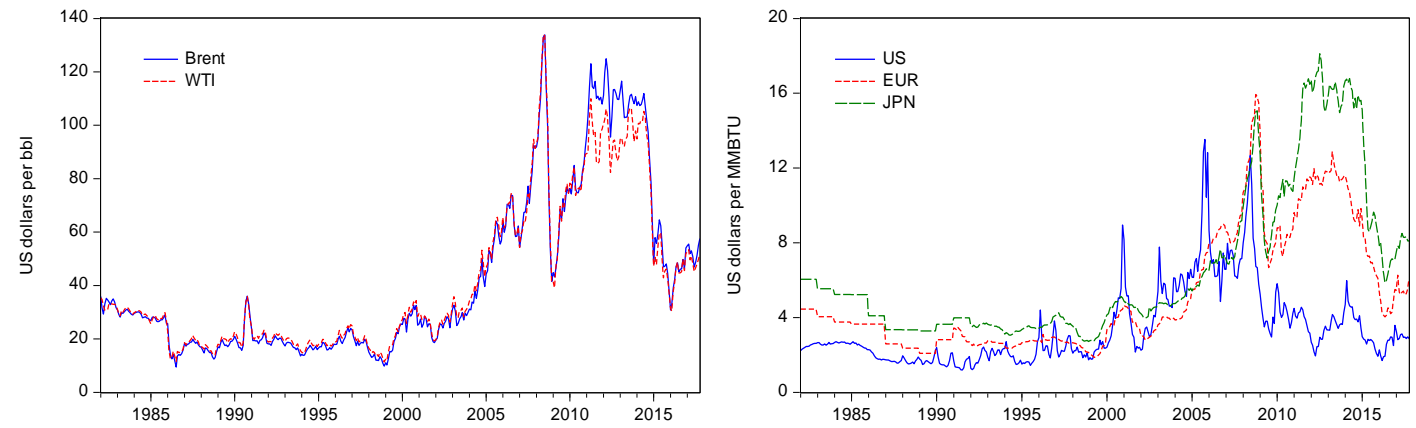

Figure 2. Oil-gas price ratios

WTI/US
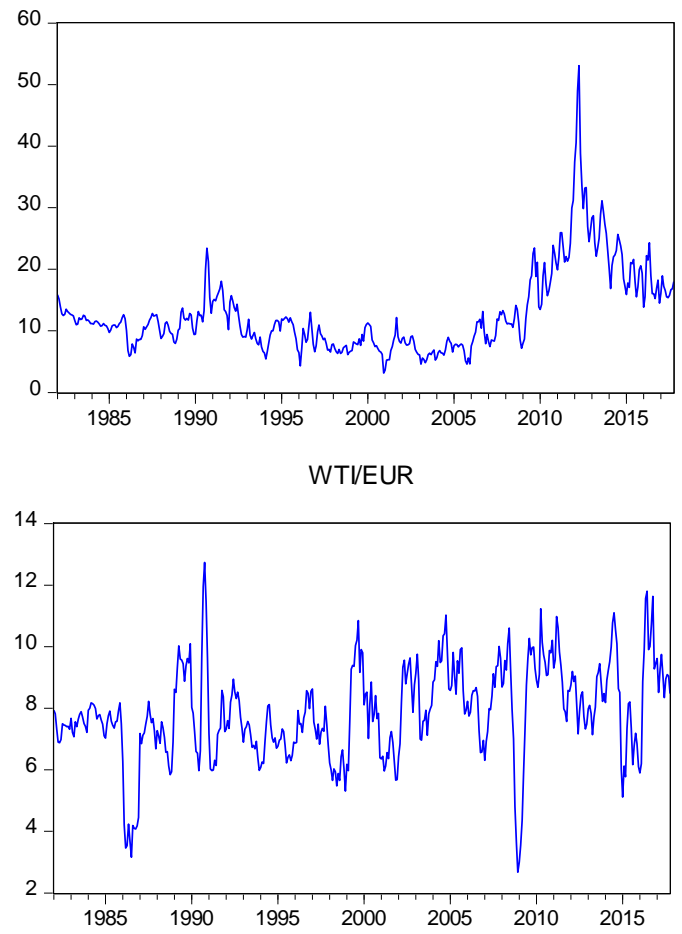

WTI/JPN

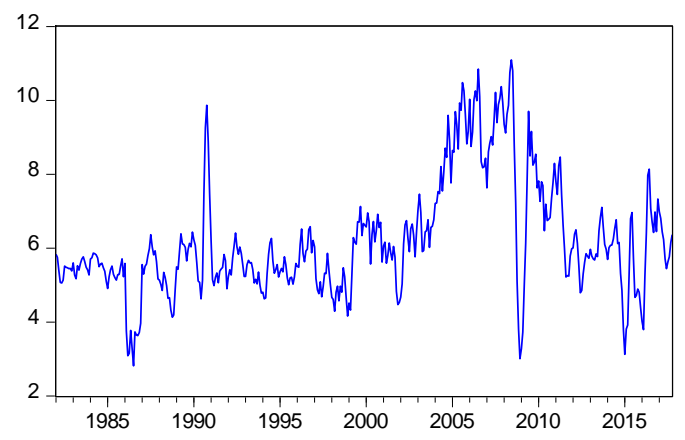

Brent/US
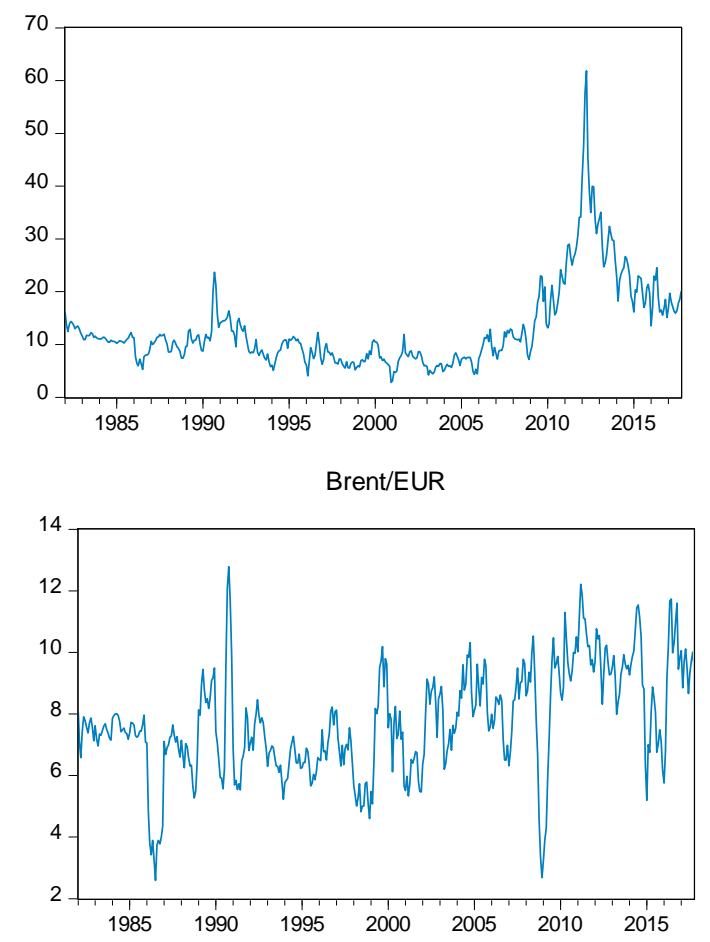

Brent/JPN

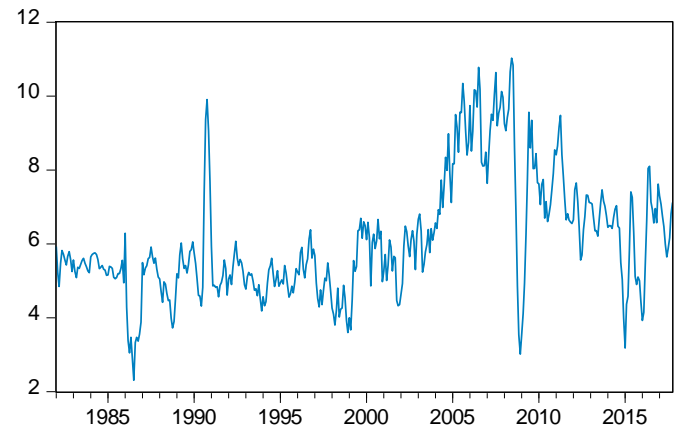


Figure 3. Multiple bubble test for the US Henry Hub prices

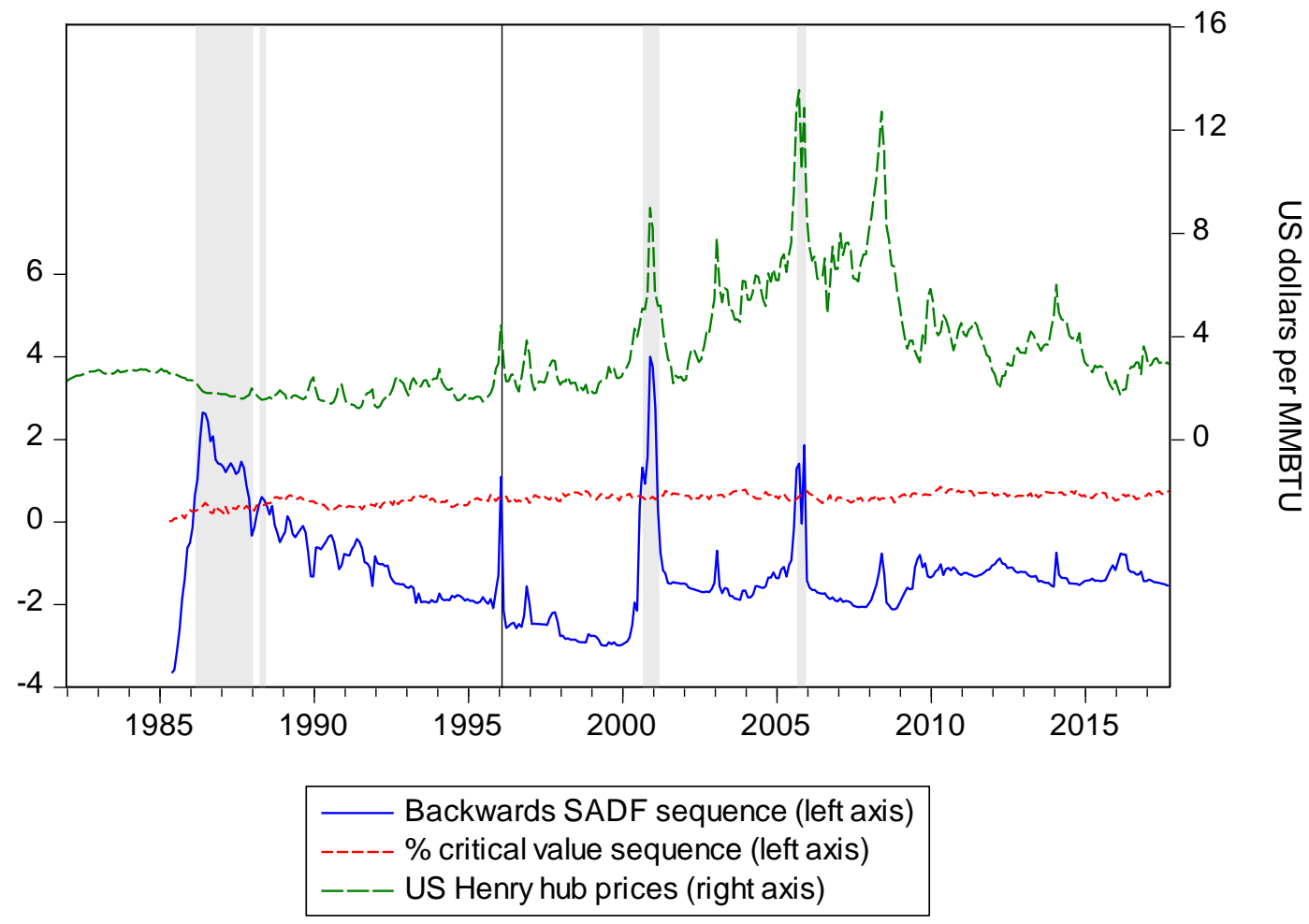

Figure 4. Multiple bubble test for the European average gas prices

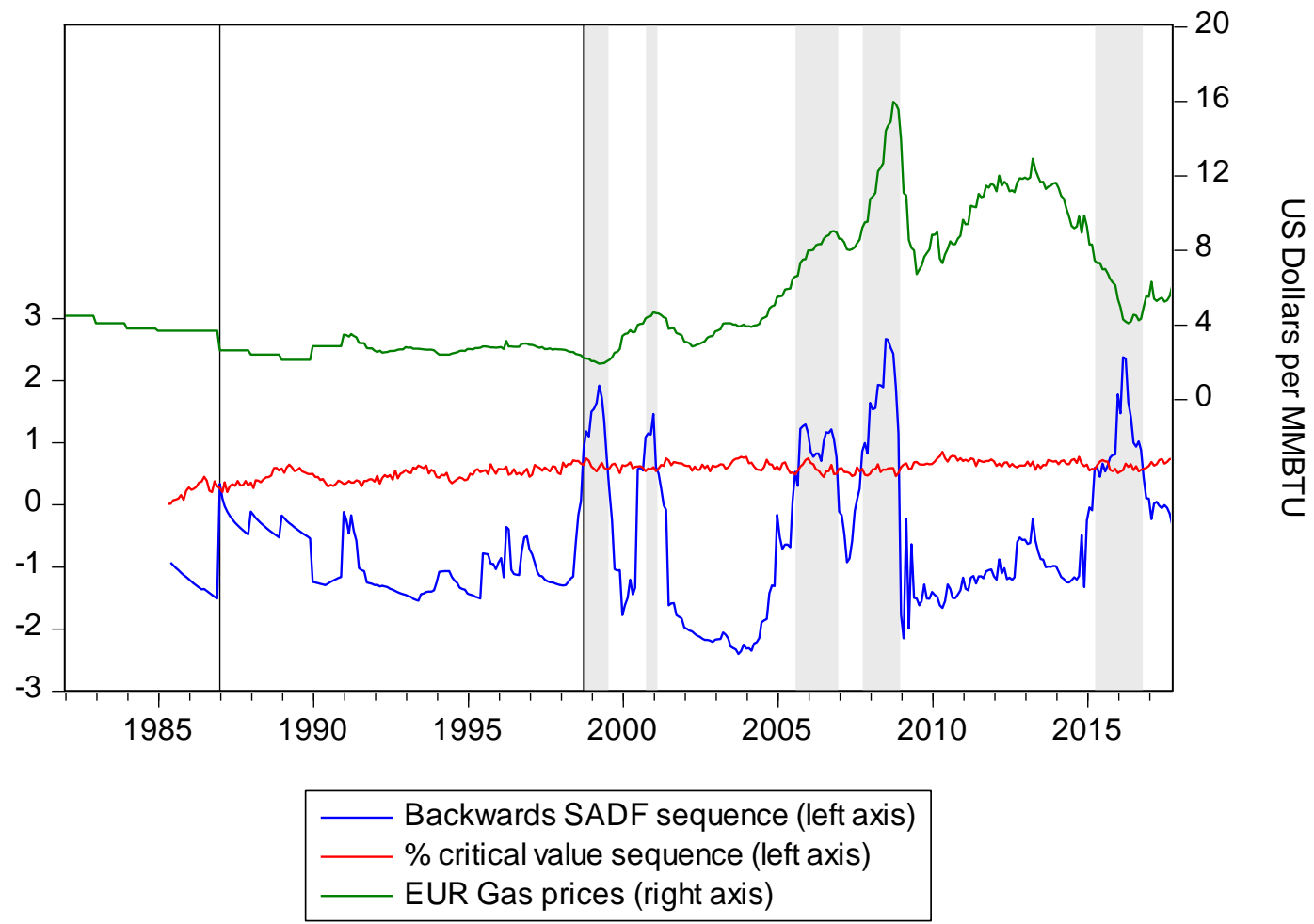


Figure 5. Multiple bubble test for the Japanese LNG prices

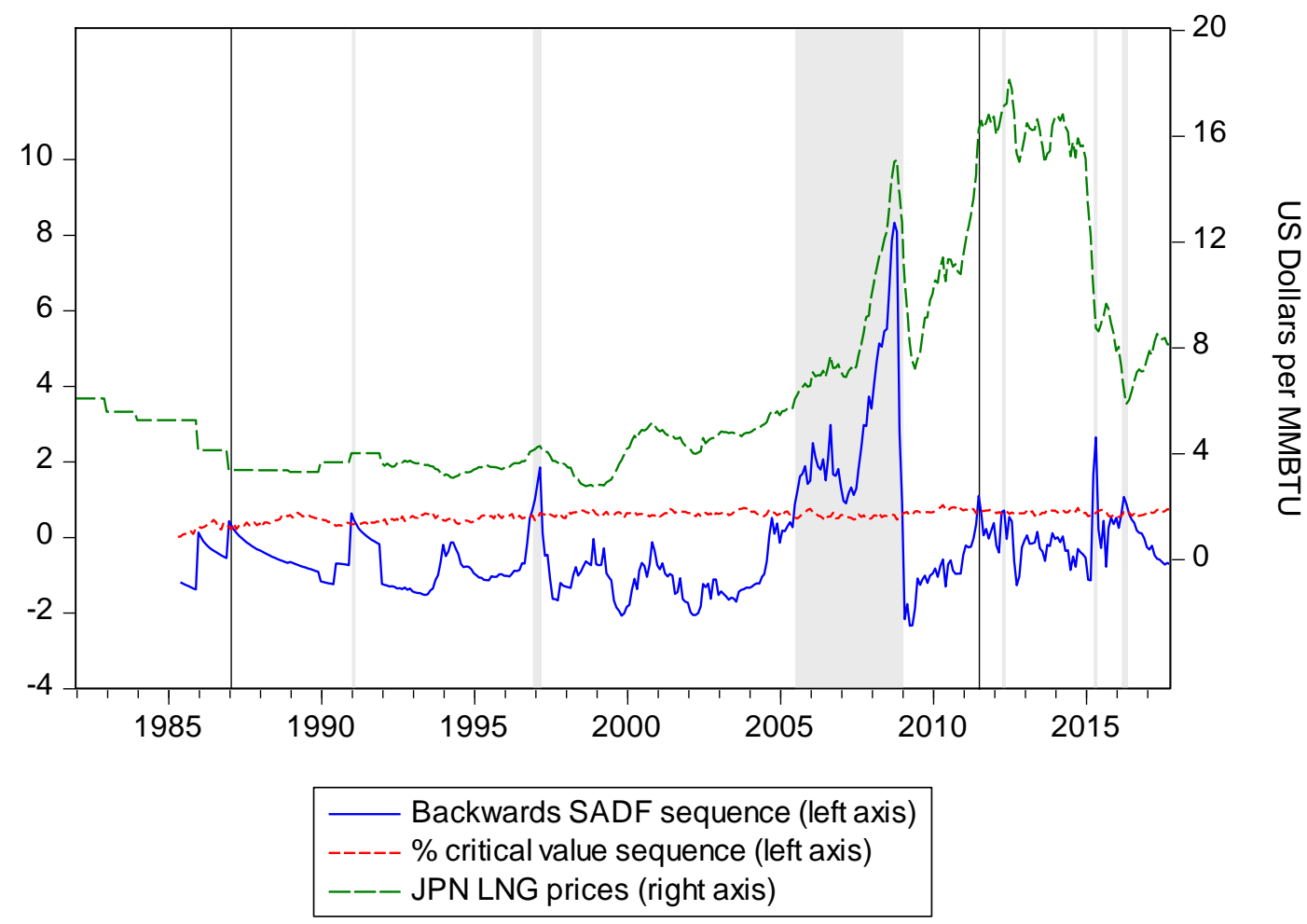

Figure 6. Multiple bubbles in Brent oil prices

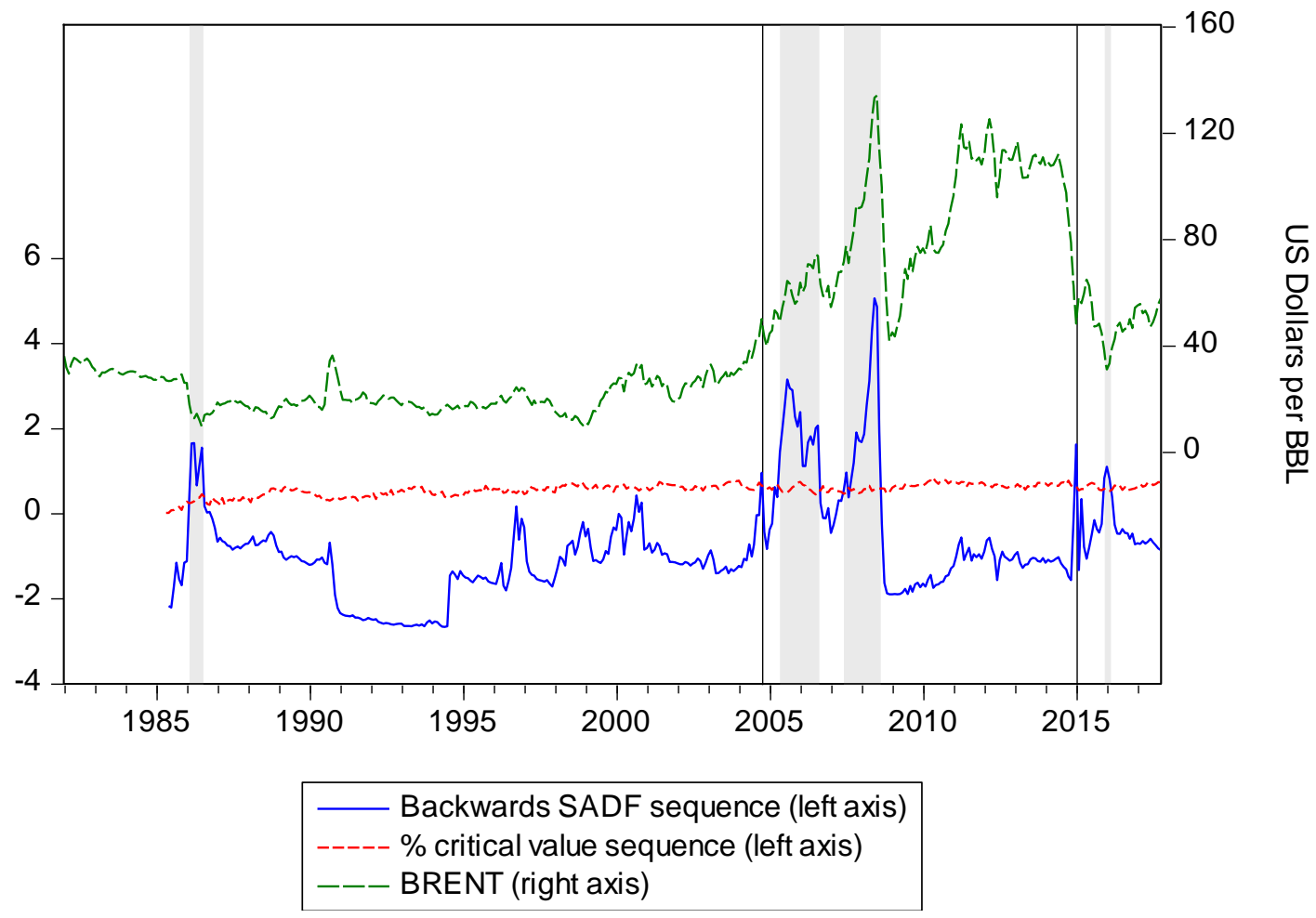


Figure 7. Multiple bubbles in the US oil-gas ratio

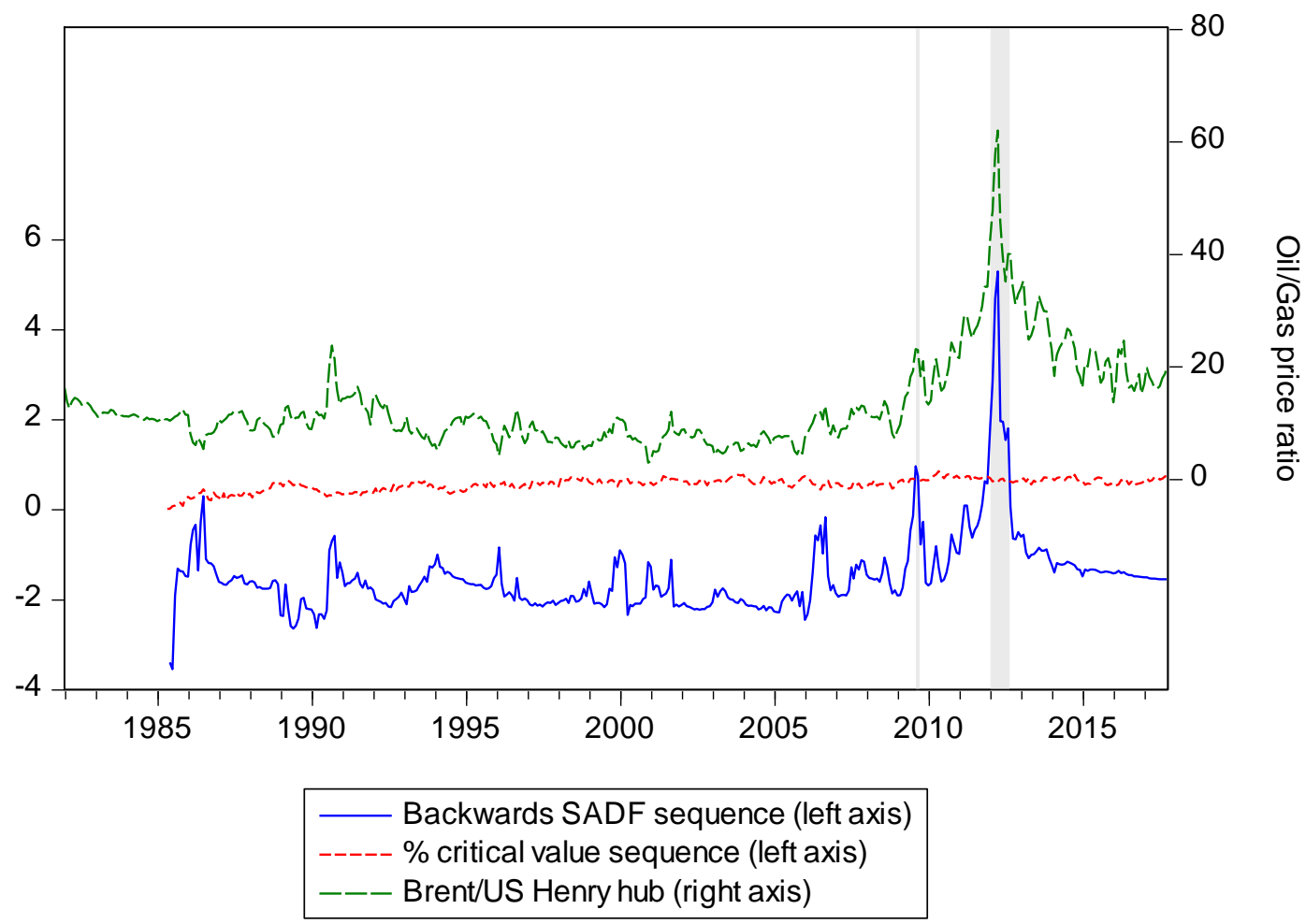

Figure 8. Multiple bubbles in the Europe oil-gas ratio

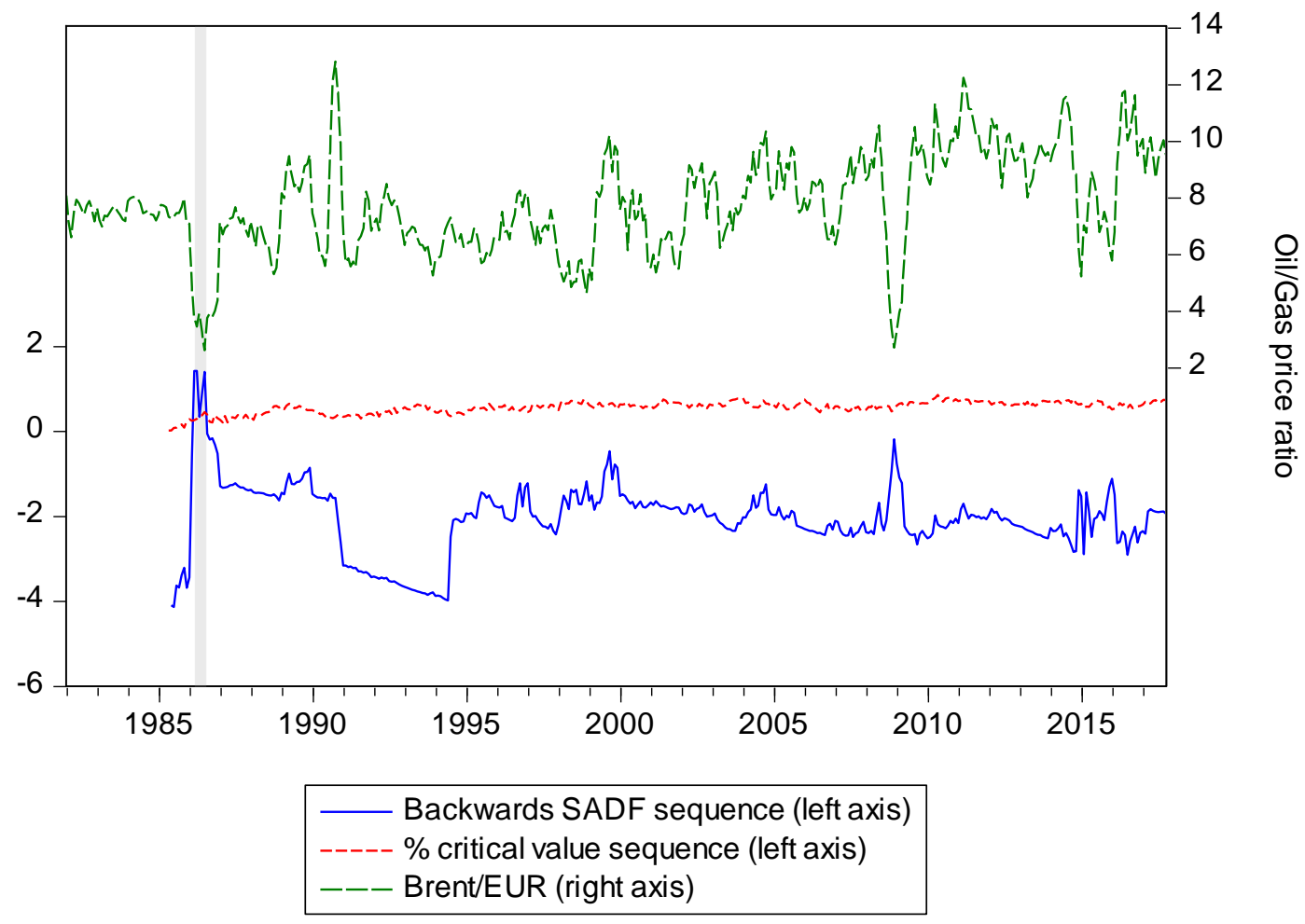


Figure 9. Multiple bubbles in the Japan oil-gas ratio

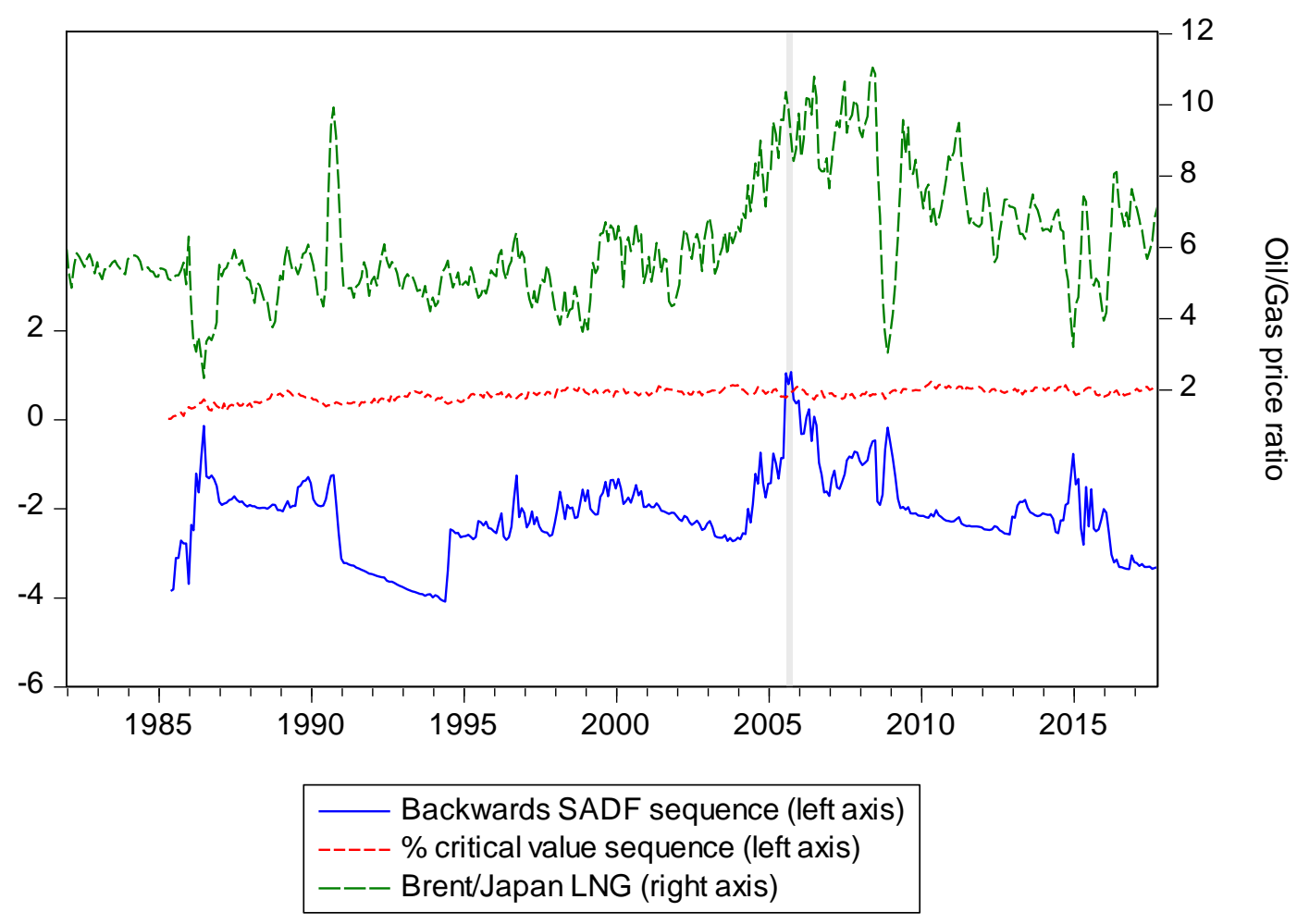

